\title{
On Nano-Oxide Coarsening Kinetics in the Nanostructured Ferritic Alloy MA957: A Mechanism Based Predictive Model
}

\author{
N.J. Cunningham*a, M.J. Alinger ${ }^{\text {al }}$, D. Klingensmith ${ }^{\mathrm{a}}$, Y. $\mathrm{Wu}^{\mathrm{a}}$, and G.R. Odette ${ }^{\mathrm{a}}$ \\ ${ }^{\text {a }}$ University of California, Santa Barbara, CA 93106, USA \\ Present Address: \\ ${ }^{1}$ GE Global Research, 1 Research Circle, MB277 Niskayuna, NY 12309, USA \\ *Corresponding author Nicholas Cunningham njc@nylerresearch.com
}

\begin{abstract}
Nanostructured ferritic alloys are dispersion strengthened and imbued with remarkable neutron irradiation damage tolerance by an ultrahigh density of nanooxide precipitates that must remain stable under prolonged high temperature service. Here, previously reported long-time and high-temperature thermal aging data is used to derive a simple, but physically based and quantitatively predictive nano-oxide coarsening model using least square fits to equations representing different underlying mechanisms. A dislocation pipe diffusion model adequately fit the data with a dislocation-detachment climb mechanism providing the best fit. This model is consistent with microstructural observations and recently reported thermo-kinetic nano-oxide nucleation, growth and coarsening simulations that rationalize the underlying physics of coarsening. It is predicted that the nano-oxides will remain fully stable up to $900^{\circ} \mathrm{C}$. This remarkable coarsening resistance is due to the extremely low matrix solubility and diffusion rate of $\mathrm{Y}$ in equilibrium with $\mathrm{Y}_{2} \mathrm{Ti}_{2} \mathrm{O}_{7}$ that activates lower resistant paths along dislocations.
\end{abstract}

KEY WORDS: Long term thermal aging; nanostructured ferritic alloy; coarsening; pipe-diffusion; nano-oxides. 


\section{Introduction}

The thermal stability of nanostructured ferritic alloys (NFAs) is critical to their use in advanced fission and future fusion reactors. NFAs are typically $14 \mathrm{Cr}, 1-3 \mathrm{~W}$ iron alloys dispersion strengthened by an ultrahigh number (order $5 \times 10^{23} / \mathrm{m}^{3}$ ) of stable Y-Ti-O nm-scale oxides (NOs) $\approx 2.5 \mathrm{~nm}$ in diameter. The stability of the NOs at expected operating temperatures of up to $\approx 800^{\circ} \mathrm{C}$ or higher is particularly important since they both strengthen the NFA and stabilize critical dislocation and grain structures [1]. In addition to high strength and creep resistance, the NOs result in remarkable resistance to neutron radiation damage [1-3]. The NOs trap and promote the recombination of excess radiation induced vacancies and selfinterstitials, and allow operation at high temperatures above the displacement damage accumulation regime. More importantly, the NOs sequester high concentrations of $\mathrm{He}$ in $\mathrm{nm}$-scale interface bubbles, greatly mitigating the otherwise enormously deleterious effect of this insoluble element, which is especially important in fusion applications.

The small NO Y-Ti-O features in MA957, and similar NFAs that are often called (X)YWT, where $\mathrm{X}$ is the $\mathrm{Cr}$ content, are primarily the complex oxide $\mathrm{Y}_{2} \mathrm{Ti}_{2} \mathrm{O}_{7}$ pyrochlore phase [2-4]. However, in this paper we refer to them simply as NOs, except in the more detailed mechanism discussion Section 5. Since NFA strength and irradiation tolerance depend on the $\mathrm{NO}$ mean diameter $(\mathrm{d})$, number density $(\mathrm{N})$ and volume fraction (f), understanding the mechanisms and associated thermodynamics and kinetics of coarsening, as well as developing predictive models, are required to qualify them for nuclear applications. 
Thermal aging studies by a number of researchers suggest the NOs in NFAs are extremely stable [5-14]. Atom probe tomography (APT) measurements showed no significant NO coarsening in a $14 \mathrm{YWT}$ NFA extruded at $850^{\circ} \mathrm{C}$ and heat-treated at $1000^{\circ} \mathrm{C}$ for $1 \mathrm{~h} \mathrm{[5].} \mathrm{Aging} \mathrm{alloy} \mathrm{MA957} \mathrm{and} \mathrm{a} \mathrm{similar} 12 \mathrm{YWT}$ at $1300^{\circ} \mathrm{C}(\sim 0.85$ of the melting temperature) for $1 \mathrm{~h}$ and $24 \mathrm{~h}$ showed only modest coarsening [6,7]. Transmission electron microscopy studies of extracted NOs following $1 \mathrm{~h}$ annealing of MA957 at $1200^{\circ} \mathrm{C}$ found slight coarsening with average particle size increasing from $\sim 2.5 \mathrm{~nm}$ to $\sim 3.5 \mathrm{~nm}[8]$.

The limits of the NO thermal stability were explored in our previous small angle neutron scattering (SANS) short-to-intermediate-term aging (SITA) study of NFA MA957 for times from 0.33 up to $480 \mathrm{~h}$ and temperatures from $1150^{\circ} \mathrm{C}$ to $1400^{\circ} \mathrm{C}$ $[9,10]$. Results show little coarsening at $1150^{\circ} \mathrm{C}$, modest and systematic coarsening at $1200^{\circ} \mathrm{C}$, and instability at and above $1250^{\circ} \mathrm{C}$. A generally similar result was obtained in another SANS and TEM study at aging temperatures from $1050^{\circ} \mathrm{C}$ to $1400^{\circ} \mathrm{C}$ at times from 1 to $10 \mathrm{~h}$. Here, coarsening was not observed up to $10 \mathrm{~h}$ at $1250^{\circ} \mathrm{C}$ but was rapid at 1300 and $1400^{\circ} \mathrm{C}$ [11]. Our previously reported very longterm thermal aging (LTTA) study of MA957 at temperatures from $800^{\circ} \mathrm{C}$ to $1000^{\circ} \mathrm{C}$ for times up to $32.4 \mathrm{kh}$ was the first to explore coarsening conditions closer to the expected maximum service temperatures and times. This study found no significant changes in either microhardness or $\mathrm{NO}$ size below $900^{\circ} \mathrm{C}$, and only modest softening (maximum $\sim 13 \% \pm 6 \%$ ) and $\mathrm{NO}$ coarsening at 950 and $1000^{\circ} \mathrm{C}[12,13]$.

While this summary demonstrates that there have been several thermal aging experiments on NFAs, few attempts have been made to quantify and model the NO 
coarsening kinetics. Williams suggested that classical Ostwald ripening models can describe NO coarsening at $1200^{\circ} \mathrm{C}$ in a 14 YWT NFA [14]. APT measurements of the average NO radius (r) were fit using a simple lattice diffusion $r=k_{1} t^{1 / 3}$ relation. Here $\mathrm{k}_{1}$ contains the classical combination of coarsening parameters $\left(\mathrm{DX}_{\mathrm{e}} \gamma\right)$, where $\gamma$ is the NO interface energy, and $X_{e}$ and $D$ are the solubility and diffusion coefficient of the rate limiting solute, respectively. However, this model does not properly account for the initial NO size. A detailed cluster dynamics (CD) thermokinetic oxide precipitate nucleation, growth and coarsening (NGC) model was recently reported [15], and is consistent with both of our LTTA [13] and SITA [10] databases for NFA MA957. The NGC CD model incorporates thermodynamic and kinetic data, along with first principle calculations for the $\mathrm{Y}$ solubility at dislocations. A pipe diffusion mechanism, where the rate limiting species $\mathrm{Y}$ dissolves onto and diffuses along, dislocations, was generally consistent with our data sets using reasonable fit parameters. However, this detailed thermo-kinetic treatment is far too complex to be a convenient engineering predictive tool, and largely confronts our aging results, rather than being simply fitted to the entire database, hence, it is quantitatively less accurate.

The goal for this work was to develop a simple, semi-empirical coarsening model that is independent of individual kinetic and thermodynamic parameters and their associated uncertainties, so as to more accurately predict long-term NO stability, while further independently exploring the coarsening mechanisms at play. The model was fit to our entire combined LTTA and SITA aging database $[10,13]$ on MA957 based mainly on SANS measurements of the NO diameter evolution. 


\section{Materials and the Aging Databases}

Alloy MA957 was originally manufactured by INCO in the late 1970s and 1980s, but is no longer commercially available. However, research continued on the remaining stock of MA957, and the alloy has been extensively characterized in many studies, reaching the status of a reference NFA. The alloying and consolidation parameters are proprietary and unknown in specific detail. However, the original patent gives the likely processing route that includes: use of -40 and -80 mesh size powders for all of the metallic alloying elements plus $\mathrm{Y}_{2} \mathrm{O}_{3}$; attritor milling for $24 \mathrm{~h}$ at $288 \mathrm{rpm}$ using a 20:1 ball to powder mass ratio; and, extruding the canned powder at $1065^{\circ} \mathrm{C}$ at a $6: 1$ ratio [16]. The nominal and measured (method not given) compositions (wt.\%) of MA957 from a previous study are shown in Table 1 [17].

Table 1. The nominal and measured composition of MA957.

\begin{tabular}{ccccccccc}
\hline wt. \% & $\mathrm{Fe}$ & $\mathrm{Cr}$ & $\mathrm{Ti}$ & $\mathrm{Mo}$ & $\mathrm{Y}$ & $\mathrm{O}$ & $\mathrm{Ni}, \mathrm{Al}, \mathrm{Mn}$ & $\mathrm{Si}, \mathrm{C}, \mathrm{S}, \mathrm{P}$ \\
\hline Nominal & bal. & 14.0 & 1.0 & 0.3 & 0.197 & 0.053 & - & - \\
Measured* & bal. & 13.87 & 1.05 & 0.30 & 0.22 & 0.22 & $<0.15$ & $<0.05$ \\
*Average measured composition from several MA957 heats [17] & &
\end{tabular}

As described above, data from our two LTTA and SITA experiments on MA957 were combined in this work. The SITA aging study was for shorter aging times, up to $480 \mathrm{~h}$, at higher temperatures from $1150^{\circ} \mathrm{C}$ to $1400^{\circ} \mathrm{C}[9,10]$. The SITA $\mathrm{d}$ versus temperature-time (T-t) database is tabulated in Table A1 in the appendix. The data is also summarized in Figure 1, showing systematic trends of increasing NO diameter minus the initial diameter $\left(d-d_{o}\right)$ as a function of T and t. The least square fit slopes of the lines are similar except for the $0.33 \mathrm{~h}$ and $480 \mathrm{~h}$ times where there is almost no coarsening. Note the SANS data are more uncertain at larger NO sizes due to the emphasis on higher scattering vector (q) regions, thus smaller precipitate sizes. The 
LTTA study was for longer times up to $32.4 \mathrm{kh}$ at temperatures from $800^{\circ} \mathrm{C}$ to $1000^{\circ} \mathrm{C}$ with the SANS d versus T-t data also summarized in Table A1.

TEM specimens from the $1000^{\circ} \mathrm{C}$ aging after $21.9 \mathrm{kh}$ were prepared by standard lift-out methods using an FEI Helios focused ion beam instrument equipped with an Omniprobe manipulator. At the final specimen thinning stage the lift-out TEM specimen was cleaned using a low energy beam $(2 \mathrm{kV}, 5.5 \mathrm{pA})$. Bright field TEM images were recorded using an FEI field emission Titan operating at 300KV.

\section{Simple Coarsening Models}

Precipitate coarsening is driven by the reduction of the total interface energy of the precipitate phase. The coarsening rates are controlled by both thermodynamics and kinetics. Thermodynamics mediates the local equilibrium between the controlling solute concentration in the precipitate and neighboring matrix. The solubility in the matrix at the interface $\left(X_{m}\right)$ is described by the Gibbs-Thomson equation, in its simplest exponential form as,

$$
\mathrm{X}_{\mathrm{m}} \approx \mathrm{X}_{\mathrm{e}} \exp \left[2 \gamma \mathrm{V}_{\mathrm{m}} / \mathrm{rRT}\right]
$$

Again $X_{e}$ is the equilibrium solubility, $\gamma$ is the interface energy, while $V_{m}$ is the molar volume, $\mathrm{r}$ is the precipitate radius while $\mathrm{R}$ and $\mathrm{T}$ are the gas constant and absolute temperature, respectively. For small values of $2 \gamma \mathrm{V}_{\mathrm{m}} / \mathrm{rRT}$ the solubility can be linearly approximated as

$$
\mathrm{X}_{\mathrm{m}} \approx \mathrm{X}_{\mathrm{e}}\left[1+2 \gamma \mathrm{V}_{\mathrm{m}} / \mathrm{rRT}\right]
$$

Thus $X_{m}>X_{e}$ increases with decreasing $r$, and coarsening occurs by the flow of solutes from smaller dissolving precipitates to larger growing precipitates. The average precipitate size and size distribution increases with time and is classically 
described by the Lifshitz-Slyozov-Wagner (LSW) theory of coarsening of a selfsimilar size distributions $[18,19]$. Note such coarsening is often called Ostwald Ripening.

The NOs are predominantly located in the matrix, not on grain boundaries; and it is the matrix NOs that primarily provide the outstanding functionality of NFA. The solute diffusion coefficient and the corresponding diffusion path control the matrix NO coarsening kinetics, which we will describe here as have a $t^{1 / p}$ time scaling. For clarity we give two simplified examples. Assuming Eq. 1b, coarsening by a lattice diffusion path, occurs at a rate $\mathrm{dr} / \mathrm{dt}$ proportional to $2 \gamma \mathrm{V}_{\mathrm{m}} / \mathrm{r}^{2} \mathrm{RT}$. Thus time integration leads to $p=3$. For pipe diffusion along dislocations $p=5$. The higher value of $p=5$ is due to the higher dimensionality in the pipe diffusion case, since the $\mathrm{dr} / \mathrm{dt}$ is also scales with the area of the dislocation core $\left(\pi \mathrm{r}_{\mathrm{c}}{ }^{2}\right)$. More generally, and considering the possibility of interface mobility controlled kinetics, $\mathrm{p}$ varies from 1 to 5; but as we will later show, $\mathrm{p}=6$ is also a possibility. More detailed and rigorous treatments can be found in $[18,19]$ and the classic publication by Ardell [20]. Note the Ardell paper appears to deal with a grain boundary coarsening path, but it actually also treats this as a process of diffusion along one to $\mathrm{n}$ dislocation pipes.

These reduced-order, linearized models can be represented by simple, yet still physically rich, equations that are convenient for fitting the coarsening data. Thus we use a coarsening expression with the general form,

$$
\left[\mathrm{d}(\mathrm{t})^{\mathrm{p}}-\mathrm{d}_{\mathrm{o}}^{\mathrm{p}}\right]=\mathrm{K}_{\mathrm{p}}(\mathrm{T}) \mathrm{t},
$$

or equivalently,

$$
\left[d(t)^{p}-d_{o}^{p}\right]^{1 / p}=\left[K_{p}(T) t\right]^{1 / p}
$$


Equation 2 for the coarsened NO diameter $[\mathrm{d}(\mathrm{t})]$ reflects integrating the effect of the average instantaneous feature size on the corresponding radial growth rate, starting at the initial, pre-aging diameter, $d_{o}$. The $K_{p}(T)$ rate coefficient contains the combination of material properties controlling the rate of coarsening and is exponentially dependent on temperature. The other material properties include the $\mathrm{Y}$ diffusion coefficient $\left(\mathrm{D}_{\mathrm{Y}}\right)$, solubility $\left(\mathrm{X}_{\mathrm{Y}}\right), \gamma$ and length scales that describe the length scale dimensionality of $K_{p}(T)$. The coarsening progresses with a $1 / p$ power of time $(\mathrm{t})$ dependence, where the $\mathrm{p}$ is specific to the coarsening mechanism in play. For example, Speight showed a one-fourth $(\mathrm{p}=4)$ coarsening dependence for precipitates on high angle grain boundaries [21]. Ardell derived the one-fifth $(p=5)$ dependence for diffusion on one to multiple (n) dislocations (for large $\mathrm{n}$, low angle grain boundaries) and refined the coarsening model to account for the precipitate volume fraction dependence [20].

Another mechanism was proposed by Vengrenovich et al. [22] for coarsening by $t^{1 / 6}$ kinetics $(p=6)$ assuming that previously pinned dislocations detach from growing precipitates and climb to add additional pipes that intersect the remaining features. More generally the detachment stress is controlled by the dislocation size dependent obstacle pinning strength, or their spacing $(\lambda)$, adding the extra unit of length-scale dimensionality to the single dislocation pipe diffusion $p=5$ case. In the following sections we apply Equation 2 to the combined MA957 aging database to derive a predictive best-fit coarsening model. 


\section{Database Least Squares Fitting}

The combined aging database was analyzed in three ways. The first approach was to use Equation $2 b$ to non-linear least square fit (LSF) the $p$ and $K(T)$ terms to the individual data sets at each temperature. As shown in Table 2, the fitted $\mathrm{p}$ is highly scattered, ranging from $\approx 1.4$ (at $950^{\circ} \mathrm{C}$ ) to $10.7\left(1300^{\circ} \mathrm{C}\right)$. The fitted $\mathrm{p}$ averaged $\approx 6.2 \pm 2.9$. Note that these fit values reflect the assumption that a given $p$ represents data at all aging times, but this may not always be the case.

Table 2. The fitted $\mathrm{p}$ for individual temperature data sets.

\begin{tabular}{ccccccccccc}
\hline $\mathrm{T}_{\mathrm{a}}{ }^{\circ} \mathrm{C}$ & 1400 & 1350 & 1300 & 1250 & 1225 & 1200 & 1175 & 1150 & 1000 & 950 \\
\hline \multirow{2}{*}{$\mathrm{p}$} & 8.1 & 9.4 & 10.7 & 6.8 & 7.5 & 5.2 & 2.6 & 3.0 & 7.7 & 1.4 \\
& \pm 2.3 & \pm 2.9 & \pm 2.9 & \pm 0.8 & \pm 0.7 & \pm 0.4 & \pm 0.3 & \pm 2.2 & \pm 14.5 &
\end{tabular}

A second approach was to LSF to all the data simultaneously, replacing the $\mathrm{k}(\mathrm{T})$ term with a common $\mathrm{k}_{\mathrm{o}} \exp \left(-\mathrm{Q}_{\mathrm{o}} / \mathrm{RT}\right)$.

$$
\left[\mathrm{d}(\mathrm{t})^{\mathrm{p}}-\mathrm{d}_{\mathrm{o}}^{\mathrm{p}}\right]^{1 / \mathrm{p}}=\left[\mathrm{k}_{\mathrm{o}} \exp \left(-\mathrm{Q}_{\mathrm{o}} / \mathrm{RT}\right) \mathrm{t}\right]^{1 / \mathrm{p}}
$$

The $\mathrm{Q}_{\mathrm{o}}$ represents the exponential temperature dependence of the $\mathrm{DX}_{\mathrm{e}}$ term. The fitting yielded $\mathrm{k}_{\mathrm{o}}=7.3 \times 10^{29} \mathrm{~nm}^{\mathrm{p}} / \mathrm{h}, \mathrm{p}=6.26 \pm 0.5$ and $\mathrm{Q}_{\mathrm{o}}=764 \pm 46 \mathrm{~kJ} / \mathrm{mole}$. The corresponding standard deviation of the predicted versus measured $\mathrm{d}$ was $\approx \pm 0.63$ nm. The fit values are summarized in Table 4. A corresponding plot of $\left[d(t)^{6.26}-\right.$ $\left.\mathrm{d}_{\mathrm{o}}{ }^{6.26}\right]^{1 / 6.26}$ versus $\mathrm{t}^{1 / 6.26}$ for all the temperatures is shown in Figure 2a. Note plotting the increase in $\mathrm{d}$ with $\mathrm{t}^{1 / \mathrm{p}}$ shows deviations from the fitted model on an appropriate physical length scale.

A third approach was to fix $\mathrm{p}$ at nominal values for a specified coarsening mechanism and LSF $K_{p}=\left[\mathrm{k}_{\mathrm{op}} \exp \left(-\mathrm{Q}_{\mathrm{op}} / \mathrm{RT}\right)\right]^{1 / \mathrm{p}}$, again at each aging temperature. The fits for $\mathrm{p}=3$ (lattice diffusion) and 5 (dislocation pipe diffusion) are shown in Figure 
$2 \mathrm{~b}$ and $\mathrm{c}$, and the corresponding $\mathrm{K}_{\mathrm{p}}$ fit values for $\mathrm{p}=3$ and 5 are summarized in Table 3. In the case of the lowest temperature $950^{\circ} \mathrm{C}$ data, the standard error in $\mathrm{K}_{\mathrm{p}}$ are $\pm 33 \%$ and $\pm 37 \%$ for $\mathrm{p}=3$ and 5 , respectively. The corresponding standard error for the $\mathrm{K}_{\mathrm{p}}$ using the $1000^{\circ} \mathrm{C}$ data are $\approx \pm 14 \%$ and $10 \%$ for $\mathrm{p}=3$ and $=5$, respectively. A power of $p=5$ provided the best fit for the majority of the 10 temperatures. The standard errors for fitted $\mathrm{K}_{\mathrm{p}}$ for all the other higher-temperature, shorter-term aging SITA data averaged $\pm 12 \%$ and $\pm 7 \%$ for $\mathrm{p}=3$ and 5 , respectively.

Table $3 . \mathrm{k}_{\mathrm{0} 3}$ or 5 fitting parameter values for assumed $\mathrm{p}=3$ or 5 coarsening.

\begin{tabular}{ccccccccccc}
\hline${ }^{\circ} \mathrm{C}$ & 1400 & 1350 & 1300 & 1250 & 1225 & 1200 & 1175 & 1150 & 1000 & 950 \\
\hline \multirow{2}{*}{$\mathrm{K}_{3}$} & 6.89 & 4.40 & 3.34 & 1.74 & 1.46 & 1.06 & 1.19 & 1.06 & 0.103 & 0.054 \\
& \pm 0.64 & \pm 0.71 & \pm 0.56 & \pm 0.17 & \pm 0.27 & \pm 0.07 & \pm 0.19 & \pm 0.07 & \pm 0.015 & \pm 0.018 \\
\cline { 2 - 11 } $\mathrm{K}_{5}$ & 8.86 & 6.37 & 4.87 & 3.31 & 2.38 & 2.21 & 2.21 & 1.60 & 0.440 & 0.235 \\
& \pm 0.64 & \pm 0.44 & \pm 0.35 & \pm 0.16 & \pm 0.14 & \pm 0.03 & \pm 0.03 & \pm 0.16 & \pm 0.043 & \pm 0.088
\end{tabular}

Figure 3 cross plots $\ln (K)=\ln \left\{\left[k_{\text {op }} \exp \left(-Q_{o p} / R T\right)\right]^{1 / p}\right\}$ versus $1 / T$ for $p=3$ and 5 to derive the corresponding activation energy, $\mathrm{Q}_{\mathrm{op}}$. Here the LSF line slope $\mathrm{m}$ is equal to $\left[\mathrm{Q}_{\mathrm{op}} / \mathrm{R}^{*} \mathrm{p}\right]$. Thus $\mathrm{Q}_{\mathrm{op}}$ is given by the product $\mathrm{R} * \mathrm{p} * \mathrm{~m}$. For $\mathrm{p}=5, \mathrm{Q}_{05} \approx$ $673 \pm 12$ and for $\mathrm{p}=3, \mathrm{Q}_{\mathrm{op}} \approx 554 \pm 11 \mathrm{~kJ} / \mathrm{mole}$. The overall predicted versus measured SD of $\left[\mathrm{d}-\mathrm{d}_{\mathrm{o}}\right]$ were 1.07 and $0.67 \mathrm{~nm}$ for $\mathrm{p}=3$ and 5 , respectively. Table 4 summarizes these results. The dashed line in Figure 3 is fit only to the high temperature data at $>1000^{\circ} \mathrm{C}$ but extrapolates very well to lower temperature data at 1000 and $950^{\circ} \mathrm{C}$. APT data from aging studies by Miller [6] on MA957 and Williams [14] on another 14YWT NFA are also shown for comparison, as the blue triangle and diamond, respectively. 
Table 4. Fit $\mathrm{Q}_{\mathrm{p}}, \mathrm{k}_{\mathrm{p}(\mathrm{o})}$ and standard deviation (SD) of the measured versus predicted $\mathrm{d}$.

\begin{tabular}{lccc}
\hline & LSF $\mathrm{p}=6.26$ & Fixed $\mathrm{p}=3$ & Fixed $\mathrm{p}=5$ \\
\hline $\mathrm{Q}_{\mathrm{p}}(\mathrm{kJ} / \mathrm{mole})$ & $764 \pm 46$ & $554 \pm 11$ & $673 \pm 12$ \\
$\mathrm{k}_{\mathrm{po}}\left(\mathrm{nm}^{\mathrm{p}} / \mathrm{h}\right)$ & $7.3 \times 10^{29}$ & $6.0 \times 10^{19}$ & $4.4 \times 10^{25}$ \\
$\mathrm{SD} \mathrm{d} \mathrm{d}_{\text {meas. }}-\mathrm{d}_{\text {predicted }}$ & 0.63 & 1.07 & 0.67 \\
$(\mathrm{~nm})$ & & & \\
\hline
\end{tabular}

The results of these LSF exercises can be summarized as follows.

- There is large scatter in the fitted $p$ values for individual data sets. This is likely associated with a combination of experimental scatter in the coarsening data itself, inadequacies in the simplified models used in the fits, and the strong covariance between the individual $\mathrm{p}$ and $\mathrm{Q}_{\mathrm{p}}$.

- The $\mathrm{p}$ fits to the overall database and the average of the fitted $\mathrm{p}$ were $\approx$ $6.26 \pm 0.5$ and $6.2 \pm 2.9$, which are larger than values for lattice and pipe diffusion coarsening models, and more consistent with a pipe diffusiondislocation detachment model [22].

- The overall predicted minus measured $\mathrm{d}(\mathrm{t}, \mathrm{T})$ standard deviations for a fixed $\mathrm{p}=5$ was relatively small at $\approx 0.6 \mathrm{~nm}$.

- The corresponding standard deviation for a fixed $\mathrm{p}=3$ for lattice diffusion is significantly larger than for $\mathrm{p}=5$ and can be rejected on a statistical basis

- Fits to the coarsening data to evaluate effective activation for coarsening, $\mathrm{Q}_{\mathrm{p}}$, are excellent in all cases.

There is a significant gap in the aging data between 1000 and $1150^{\circ} \mathrm{C}$ that could be filled in the future to better discriminate between the $\mathrm{p}=5$ and $\approx 6$ models. However, more precise model selection is confounded by the strong covariance between $\mathrm{p}$ and $\mathrm{Q}_{\mathrm{p}}$. That is, fixing $\mathrm{p}$ at 5 and 6 results in predicting similar $\mathrm{d}$ because of the covariant changes in the corresponding simultaneously fitted $\mathrm{Q}_{\mathrm{p}}$. Thus reliably discriminating between the $\mathrm{p}=5$ and 6 models would require very long aging times. For example, aging at $1100^{\circ} \mathrm{C}$ would require aging $\approx 200 \mathrm{kh}$ to reach an 
approximately $20 \%$ difference in NO size between the predicted $\mathrm{d}$ of $11.8 \mathrm{~nm}$ for $\mathrm{p}=$ 5 and $9.4 \mathrm{~nm}$ for $\mathrm{p}=6$. Given the insensitivity of the predicted $\mathrm{d}$ to the value of $\mathrm{p}$ in the range of roughly 5 to 6 , we believe the $\mathrm{p}=5$, pipe diffusion model is adequate for practical engineering prediction purposes, especially since it can easily be physically parameterized. The numerical $p=5$ expression is given in Equation A1 in the appendix.

To further illustrate this point, Figure 4a shows the predictions of the three models at $150,000 \mathrm{~h}$ as a function of temperature up to $1000^{\circ} \mathrm{C}$ for $\mathrm{d}_{\mathrm{o}}=2.68 \mathrm{~nm}$. Using $\mathrm{p}=3$ predicts a faster coarsening rate compared to the $\mathrm{p}=5$ or 6.3 models. However, the difference in $\mathrm{d}$ between $\mathrm{p}=5$ and 6.3 at $1000^{\circ} \mathrm{C}$ is only $\approx 0.5 \mathrm{~nm}$, or less than $12 \%$. In all cases it is clear that the NO coarsening rates are negligible below $\approx 950^{\circ} \mathrm{C}$. Figure $4 \mathrm{~b}$ plots the time needed to double $\mathrm{d}_{\mathrm{o}}$ as a function of $1 / \mathrm{T}$ for the $\mathrm{p}=5$ model.

For perspective, the $\mathrm{p}=5$ model predicts that at $1000^{\circ} \mathrm{C}$ a $2.68 \mathrm{~nm} \mathrm{NO}$ would double in size at $\approx 10^{5} \mathrm{~h}$ while at $800^{\circ} \mathrm{C}$ this would take $>10^{8} \mathrm{~h}$. The aged data can be used along with the size dependent obstacle strengthening contribution model, derived by Alinger, to predict the reduction in strength associated with NO coarsening [1]. Of course, the NOs contribute only one component of the NFA strength, which is also provided by dislocations and grain boundaries. Aging at $1000^{\circ} \mathrm{C}$ for $19.5 \mathrm{kh}$ resulted in no observable changes in the dislocation structure and grain size [13]. The precipitate strength contribution model is proportional to $\approx \kappa \sqrt{ } \mathrm{f} / \mathrm{d}$ where $\kappa$ is an effective dislocation obstacle strength factor $[8,23,24]$. The Hall-Petch contribution is given by $\mathrm{k} / \mathrm{d}_{\mathrm{g}}$ where $\mathrm{d}_{\mathrm{g}}$ is the grain diameter [13]. Using the nominal 
SANS data for $\mathrm{f}$ and $\mathrm{d}$, and recent estimates of $\mathrm{k}=12500 \mathrm{MPa}-\mathrm{nm}$ and an unaged yield stress of $\sigma_{\mathrm{y}}=850 \mathrm{MPa}$ for MA957 [1,23], the reductions in strength are predicted to be $\approx 20$ and $12 \%$ (averaging $16 \%$ ) for 19.5 and $21 \mathrm{kh}$ at $1000^{\circ} \mathrm{C}$, respectively; this compares favorably to the corresponding observed values of $13 \%$ and $7 \%$ (averaging 10\%). Given the uncertainties in the measurements and simplicity of the models, the agreement is reasonable. Further, at $19.5 \mathrm{kh}$ the corresponding predicted strength reductions are 12 and 18\% (averaging 15\%) for the TEM and APT data, respectively.

Additional characterization of grain growth and dislocation recovery kinetics (if any) would be needed to develop an overall model for the evolution of NFA strength as a function of aging time and temperature. However, this is beyond the scope of this paper. Our major conclusion is that softening is likely to be negligible at service temperatures up to $850^{\circ} \mathrm{C}$ even for very long service times.

\section{Coarsening Mechanisms}

As shown elsewhere, the NOs in MA957 are primarily the pyrochlore $\mathrm{Y}_{2} \mathrm{Ti}_{2} \mathrm{O}_{7}$ complex oxide [2-4]. Thus for near-equilibrium conditions, the matrix solubility of $\mathrm{Y}, \mathrm{X}_{\mathrm{Ym}}$, would be controlled by this phase and the matrix Ti and $\mathrm{O}$ activities [15]. Assuming $\mathrm{Ti}$ is in equilibrium with the metallic phase, the critical solute activity controlling $\mathrm{X}_{\mathrm{Ym}}$ is the $\mathrm{O}$ partial pressure, $\mathrm{P}_{\mathrm{O} 2}$. The predicted matrix solubility, $\mathrm{X}_{\mathrm{Ym}} \approx$ $4.7 \times 10^{-29}$ at $1000^{\circ} \mathrm{C}$, is clearly the rate controlling mechanism [15]. The low $\mathrm{Y}$ solubility is due to the very high stability of the $\mathrm{Y}_{2} \mathrm{Ti}_{2} \mathrm{O}_{7}$ phase and the high solution enthalpy for Y. Assuming lattice diffusion controlled kinetics $(\mathrm{p}=3)$, the classical NO coarsening rate is given by [20] 


$$
\left\{\left[\mathrm{d}(\mathrm{t})^{3}-\mathrm{d}_{\mathrm{o}}{ }^{3}\right] / \mathrm{t}\right\}^{1 / 3} \approx \mathrm{K}_{3} \approx\left[7 \gamma \mathrm{V}_{\mathrm{m}} \mathrm{D}_{\mathrm{Ym}} \mathrm{X}_{\mathrm{Ym}} / \mathrm{RT}\right]^{1 / 3} \mathrm{~nm} / \mathrm{h}^{1 / 3}
$$

Here, the experimental estimate of $D_{Y m}$ is the matrix diffusion coefficient of $\mathrm{Y}$ in ferrite $\left(\approx 9 \times 10^{-16} \mathrm{~m}^{2} / \mathrm{s}\right.$ at $\left.1000^{\circ} \mathrm{C}\right)[15], \gamma$ is the NO-matrix interface energy $(\approx 1.2$ $\left.\mathrm{J} / \mathrm{m}^{2}\right)$ from [15] and $\mathrm{V}_{\mathrm{m}}$ is the ferrite molar volume $\left(\approx 7 \times 10^{-6} \mathrm{~m}^{\wedge} 3 / \mathrm{mole}\right)$. Equation 4 yields a predicted coarsening rate $\left.\left[\mathrm{d}(\mathrm{t})^{3}-\mathrm{d}_{\mathrm{o}}{ }^{3}\right] / \mathrm{t}\right]^{1 / 3} \approx 10^{-7} \mathrm{~nm} / \mathrm{h}^{1 / 3}$ compared to the measured value of $1.1 \times 10^{-3} \mathrm{~nm} / \mathrm{h}^{1 / 3}$. Thus the $\left[7 \gamma \mathrm{VD}_{\mathrm{m}} \mathrm{X}_{\mathrm{m}} / \mathrm{RT}\right]$ term would have to be $1.33 \times 10^{12}$ times larger to explain the observed coarsening rate.

Assuming Henry's law behavior, the $\mathrm{X}_{\mathrm{Ym}}$ is equivalent to an effective solution energy for $\mathrm{Y}$ near $1000^{\circ} \mathrm{C} \approx 698 \mathrm{~kJ} /$ mole. Adding a calculated $\mathrm{Y}$ matrix diffusion activation energy of $218 \mathrm{~kJ} / \mathrm{mole}$ [15] to this value results in an overall activation energy for matrix NO coarsening of $\approx 916 \mathrm{~kJ} / \mathrm{mole}$, which is 1.6 times higher than for the $\mathrm{p}=3$ model fit of $555 \mathrm{~kJ} / \mathrm{mole}$ found in this study. Clearly the lattice $\mathrm{Y}$ dissolution-diffusion mechanism is not consistent with experiment.

The data is better fit by a dislocation pipe diffusion mechanism $(p=5)$. The TEM micrographs in Figure $5 \mathrm{a}$ and $\mathrm{b}$ for the $1000^{\circ} \mathrm{C}$ and $21.9 \mathrm{kh}$ aged condition show most of the NOs are associated with dislocations. Neglecting the volume fraction effects, classical NO coarsening by dislocation pipe diffusion [20] is given by,

$$
\left\{\left[\mathrm{d}(\mathrm{t})^{5}-\mathrm{d}_{\mathrm{o}}{ }^{5}\right] / \mathrm{t}\right\}^{1 / 5}=\mathrm{K}_{5}=\left\{32 \mathrm{~A} \gamma \mathrm{VD}_{\mathrm{Yd}} \mathrm{X}_{\mathrm{Yd}} / \mathrm{RT}\right\}^{1 / 5}
$$

Here, $\mathrm{A}$ is the cross section area for pipe diffusion (taken as $\approx 4 \mathrm{~b}^{2} \approx 2.5 \times 10^{-19} \mathrm{~m}^{2}$ ). Coarsening on dislocations is consistent with a much higher value of $\mathrm{D}_{\mathrm{Y}} \mathrm{X}_{\mathrm{Y}}$. The binding energy of $\mathrm{Y}$ to dislocations was determined by first principal calculations to be $\approx 241.2 \mathrm{~kJ} / \mathrm{mole}$ [15]. Further, assuming that the $\mathrm{Y}$ diffusion activation energy at 
dislocations is reduced by a typical factor of 2 , to $\approx 109 \mathrm{~kJ} / \mathrm{mole}$, and ignoring differences in the pre-exponential factor, the dislocation $\mathrm{D}_{\mathrm{Yd}} \mathrm{X}_{\mathrm{Yd}}$ term is $\approx 5.4 \times 10^{14}$ times higher than the corresponding matrix $\mathrm{D}_{\mathrm{Ym}} \mathrm{X}_{\mathrm{Ym}}$. The absolute coarsening rate is predicted to be $\approx 0.054 \mathrm{~nm} / \mathrm{h}^{1 / 5}$, much closer to the measured value of $0.085 \mathrm{~nm} / \mathrm{h}^{1 / 5}$. Using the parameters given above, the nominal value of the $\left\{32 \mathrm{~A} \gamma \mathrm{VD}_{\mathrm{Yd}} \mathrm{X}_{\mathrm{Yd}} / \mathrm{RT}\right\}$ term for the $\mathrm{p}=5$ model is only $\approx 10.3$ lower. This is considered to be very good agreement, and the $\mathrm{p}=5$ pipe diffusion model is clearly far superior to the $\mathrm{p}=3$ lattice diffusion model. Based on the assumption the net activation energy for $\mathrm{D}_{\mathrm{Yd}} \mathrm{X}_{\mathrm{Yd}}$ can be approximated as $698-250=448 \mathrm{~kJ} / \mathrm{mole}$ and that for pipe diffusion the activation energy is $109 \mathrm{~kJ} / \mathrm{mole}$, the overall activation energy for $\mathrm{D}_{\mathrm{Yd}} \mathrm{X}_{\mathrm{Yd}}$ is $\approx$ $557 \mathrm{~kJ} / \mathrm{mole}$, or about a factor of $\approx 0.82$ lower than the fitted value. Note the free energy difference driving coarsening of $\approx 4 \gamma \mathrm{V}_{\mathrm{m}} / \mathrm{d}$ is enormously smaller by comparison, at only $\approx 12.9 \mathrm{~kJ} / \mathrm{mole}$.

The $\mathrm{p}=5$ results can be compared to the detailed thermo-kinetic model reported in reference [15]. Note, the more complex physical model was fit only to the longest time coarsening data, and generally over predicts $d$ at shorter time, corresponding to a higher effective p. However, fits to the temperature dependence predicted by the model yield an effective activation energy of $694 \mathrm{~kJ} / \mathrm{mole}$, which is very close to the experimental value of $673 \pm 12 \mathrm{~kJ} /$ mole for the $\mathrm{p}=5$ model.

While the $\mathrm{p}=5$ model is far superior to that for $\mathrm{p}=3$, the overall kinetics are slightly better fit by a $\mathrm{p} \approx 6$ time scaling. Although we do not propose a quantitative model, it is noted that $\mathrm{p} \approx 6$ kinetics is rationalized by a mechanism that also considers dislocation climb. We hypothesize that climb provides a larger number of 
intersections between the NOs and the dislocation pipes. As the NOs coarsen, the threshold $\sigma_{\mathrm{c}}$ stress for Nabarro-Herring climb would decrease with increasing $\mathrm{d}$ and decreasing $\mathrm{N}$ roughly in proportion to the precipitate spacing, $\lambda$, as $\sigma_{\mathrm{c}} \alpha 1 / \lambda$. This concept leads to a higher $\mathrm{p}$ and is similar to the theory proposed by Vengrenovich et al. who show that coarsening by pipe-diffusion along dislocations that are able to detach from precipitates and climb as the stress fields are reduced around growing precipitates also yields $\mathrm{p}=6[22]$.

The tremendous resistance to oxide coarsening in MA957 may suggest the need for new ways of thinking about far from equilibrium material states, where classical near equilibrium concepts no longer directly apply. In this particular example, the Fe-Y-Ti-O system was pushed very far from equilibrium during mechanical alloying that forces $\mathrm{Y}$ into solution prior to precipitation during high temperature powder consolidation. In order to coarsen, the Y must somehow re-dissolve, which is the rate controlling process due to its very low solubility in Fe. The dissolution rate is very slow since the activation energies remain high, while the thermal driving free energy is very low. Dissolution rates may also be decreased by non-equilibrium oxygen activities that drive the $2 \mathrm{Ti}+2 \mathrm{Y}+7 \mathrm{O}->\mathrm{Y}_{2} \mathrm{Ti}_{2} \mathrm{O}_{7}$ reaction in the forward oxidation direction. Apparently, dislocations provide a slow, but finite, solubility-diffusion path. However, the resulting kinetics remains highly frustrated, providing an unprecedented degree of effective NO precipitate stability. The NO-ferrite matrix system is effectively trapped, and almost frozen, in a metastable state up to very high service temperatures, even for nm-scale features. 


\section{Summary and Conclusions}

The LTTA results from our previous study for temperatures up to $1000^{\circ} \mathrm{C}$ [13] were combined with our SITA data reported by Alinger $[9,10]$ for aging MA957 at higher temperatures from $1150^{\circ} \mathrm{C}$ to $1400^{\circ} \mathrm{C}$ and shorter times from 0.33 to $480 \mathrm{~h}$. The model equations were fit to the data three different ways. First, individual fits to each temperature data showed large scatter, but averaging the fitting parameter values gave a $\mathrm{p}=6.2 \pm 2.9$, which is most consistent with a dislocation detachmentclimb pipe diffusion mechanism. Fitting all the data simultaneously gave a similar $\mathrm{p}$ $=6.28 \pm 0.5$ and an activation energy of $764 \pm 46 \mathrm{~kJ} / \mathrm{mole}$. Equations holding the $\mathrm{p}$ values fixed for lattice diffusion $(\mathrm{p}=3)$ or pipe diffusion $(\mathrm{p}=5)$ were used to determine the activation energy and coarsening pre-exponential coefficients. The $p=$ 3 model can be rejected on both a statistical and mechanistic basis. The $\mathrm{p}=5$ model is consistent with microstructural observations of dislocation-NO associations during aging, and mechanistic assessments of the predicted coarsening rates. The covariance between the value of $p$ and $Q_{p}$ reduces the sensitivity of the predicted $d$ to the specific value selected. Thus the $\mathrm{p}=5$ model is sufficiently robust for practical purposes. Both $\mathrm{p}=5$ and $\approx 6$ models indicates that the NOs will remain effectively fully stable for temperatures up to $900^{\circ} \mathrm{C}$.

The remarkable coarsening resistance is due to the low solubility of $\mathrm{Y}$ in equilibrium with $\mathrm{NO} \mathrm{Y}_{2} \mathrm{Ti}_{2} \mathrm{O}_{7}$ precipitates, which is the rate-controlling step. Indeed, it appears that sufficient solubility and diffusion rates occur only on dislocations, leading to a pipe diffusion mechanism. 
One final caveat is in order. The MA957 characterized in this study was most likely extruded at $\approx 1065^{\circ} \mathrm{C}$. Thus future work will be directed at the effects of lower consolidation temperature on the NO and NFA stability.

\section{Acknowledgments}

This work was primarily supported by the DOE Office of Fusion Energy (DEFG03-94ER54275). We also acknowledge the support of the National Institute of Standards and Technology, US Department of Commerce, in providing the neutron research facilities (NIST Center for Neutron Research) used in this work.

\section{Appendix}

Table A1. NO d (nm) in alloy MA957 as a function of aging time and temperature determined by SANS measurements $[9,10,13]$

\begin{tabular}{|c|c|c|c|c|c|c|c|c|c|c|c|c|}
\hline \multirow[b]{3}{*}{$\mathrm{t}(\mathrm{h})$} & \multirow{2}{*}{$\frac{\mathrm{T}\left({ }^{\circ} \mathrm{C}\right)}{950}$} & \multicolumn{3}{|c|}{$\mathrm{T}\left({ }^{\circ} \mathrm{C}\right)$} & \multicolumn{8}{|c|}{$\mathrm{T}\left({ }^{\circ} \mathrm{C}\right)$} \\
\hline & & \multirow[b]{2}{*}{$\mathrm{t}(\mathrm{h})$} & \multirow{2}{*}{$\frac{1000}{\mathrm{~d}(\mathrm{~nm})}$} & \multirow[b]{2}{*}{$\mathrm{t}(\mathrm{h})$} & 1150 & 1175 & 1200 & 1225 & 1250 & 1300 & 1350 & 1400 \\
\hline & $\mathrm{d}(\mathrm{nm})$ & & & & \multicolumn{8}{|c|}{$\mathrm{d}(\mathrm{nm})$} \\
\hline 3000 & 2.73 & 3000 & 3.26 & 0.33 & - & - & - & 2.92 & 3.18 & - & - & - \\
\hline 6600 & 2.64 & 4000 & 2.82 & 3 & 2.76 & 2.82 & 3.26 & 3.54 & 5.30 & 7.26 & 9.68 & 11.86 \\
\hline 9600 & 2.65 & 8000 & 2.82 & 9 & 2.88 & - & 3.68 & - & 6.30 & 8.00 & 9.96 & 13.08 \\
\hline 17700 & 2.85 & 11000 & 3.47 & 27 & 2.90 & - & 4.32 & 5.18 & 6.44 & 8.32 & 11.14 & - \\
\hline \multirow[t]{3}{*}{31200} & 3.46 & 19500 & 3.87 & 81 & 2.90 & - & 5.12 & - & 7.44 & - & - & - \\
\hline & & 21900 & 2.94 & 243 & 6.46 & 5.28 & 6.86 & 6.50 & 9.18 & - & - & - \\
\hline & & & & 480 & 5.58 & 6.68 & 7.44 & - & - & - & - & - \\
\hline
\end{tabular}

$\mathrm{d}_{\mathrm{o}}=2.64 \mathrm{~nm}$ for $\mathrm{T}>1000^{\circ} \mathrm{C}$ and $2.68 \mathrm{~nm}$ for $\mathrm{T}=950$ and $1000^{\circ} \mathrm{C}$

In absolute terms the $\mathrm{p}=5$ coarsening equation for MA957 is given by

$$
\begin{aligned}
\mathrm{d}(\mathrm{T}, \mathrm{t}) & =\left[\mathrm{k}_{5 \mathrm{o}} \exp \left(-\mathrm{Q}_{5 \mathrm{o}} / \mathrm{RT}\right) \mathrm{t}-\mathrm{d}_{\mathrm{o}}^{\mathrm{p}}\right]^{1 / \mathrm{p}} \\
& =\left[4.4 \times 10^{25} \mathrm{~nm}^{5} / \mathrm{h} \cdot \exp \left(-673 \mathrm{~kJ} / \mathrm{mol} /\left(8.314 \mathrm{JK}^{-1} \mathrm{~mol}^{-1} \cdot \mathrm{T}\right)\right) \mathrm{t}-\mathrm{d}_{\mathrm{o}}^{5}\right]^{1 / 5}
\end{aligned}
$$




\section{REFERENCES}

1. G.R. Odette, M.J. Alinger, and B.D. Wirth, Annual Review of Materials Research, Vol. 38, 2008, 472.

2. Y. Wu, E.M. Haney, N.J. Cunningham, G.R. Odette, Acta Mater. 60, 2012, 3456-3468.

3. J. Ribis and Y. de Carlan, Acta Mater., 60, 2012, 238-252.

4. G.R. Odette, J. of Mater., 66, 2014, 2427-2441.

5. M.K. Miller, K.F. Russell and D.T. Hoelzer, J. Nucl. Mater., 351, 2006, 261268.

6. M.K. Miller, D.T. Hoelzer, E.A. Kenik and K.F. Russell, J. Nucl. Mater., 329, 2004, 338-341.

7. M.K. Miller, D.T. Hoelzer, E.A. Kenik and K.F. Russell, Intermetallics, 329, 2005, 387-392.

8. H. Sakasegawa, F. Legendre, L. Boulanger, L. Chaffron, T. Cozzika, J. Malaplate, J. Henry, Y. de Carlan and M. Brocq, Mater. Res. Soc. Symp. Proc. Vol 1125, 2009.

9. M.J. Alinger, On the Formation and Stability of Nanometer Scale Precipitates in Ferritic Alloys during Processing and High Temperature Service, Thesis (PhD), University of California Santa Barbara, 2004

10. M.J. Alinger, G.R. Odette, and D.T. Hoelzer, J. Nucl. Mater., 329-333, 2004, 382-386.

11. S.Y. Zhong, J. Ribis, V. Klosek, Y. de Carlan, N. Locket, V. Ji, and M.H. Mathon, J. Nucl. Mater., 428, 2012, 154-159.

12. P. Miao, G.R. Odette, T. Yamamoto, M. Alinger, and D. Klingensmith, J. Nucl. Mater., 377, 2008, 59-64.

13. N. Cunningham, Y. Wu, D. Klingensmith, and G.R. Odette, Mater. Sci. and Engr. A, 613, 2014, 296-305.

14. C.A. Williams, G.D.W. Smith, E.A. Marquis, Scripta Mater., 67, 2012, 108-111.

15. L. Barnard, N. Cunningham, G.R. Odette, I. Szlufarska, and D. Morgan, Acta Mater., 91, 2015, 340-354.

16. J.J. Fisher, U.S. Patent No. 4,075,010, 1978.

17. H.L. Hamilton, D.S. Gelles, R.J. Lobsinger, G.D. Johnson, W.F. Brown, M.M. Paxton, R.J. Puigh, C.R. Eiholzer, C. Martinez, and M.A. Blotter, Technical Report PNL-13168, 1991

18. I.M. Lifshitz and V.V. Slyzov, J. Phys. Chem. Solids, 19, 1961, 35.

19. C. Z. Wagner, Electrochem, 65, 1961, 581.

20. A.J. Ardell, Acta Metall., 20, 1972, 601-609. 
21. M.V. Speight, Acta Metall. Trans., 20, 1972, 61.

22. R.D. Vengrenovich, Y.V. Gudyma, and S.V. Yarema, Scripta Mater., 46, 2002, 363-367.

23. N. Cunningham, Y. Wu, A. Etienne, E.M. Haney, G.R. Odette, E. Stergar, D.T. Hoelzer, Y.D. Kim, B.D. Wirth, and S.A. Maloy, J. Nucl., Mater., 444, 2014, $35-$ 38 .

24. J. W. Martin, Micromechanisms in Particle Hardened Alloys, Cambridge Press (1980) 


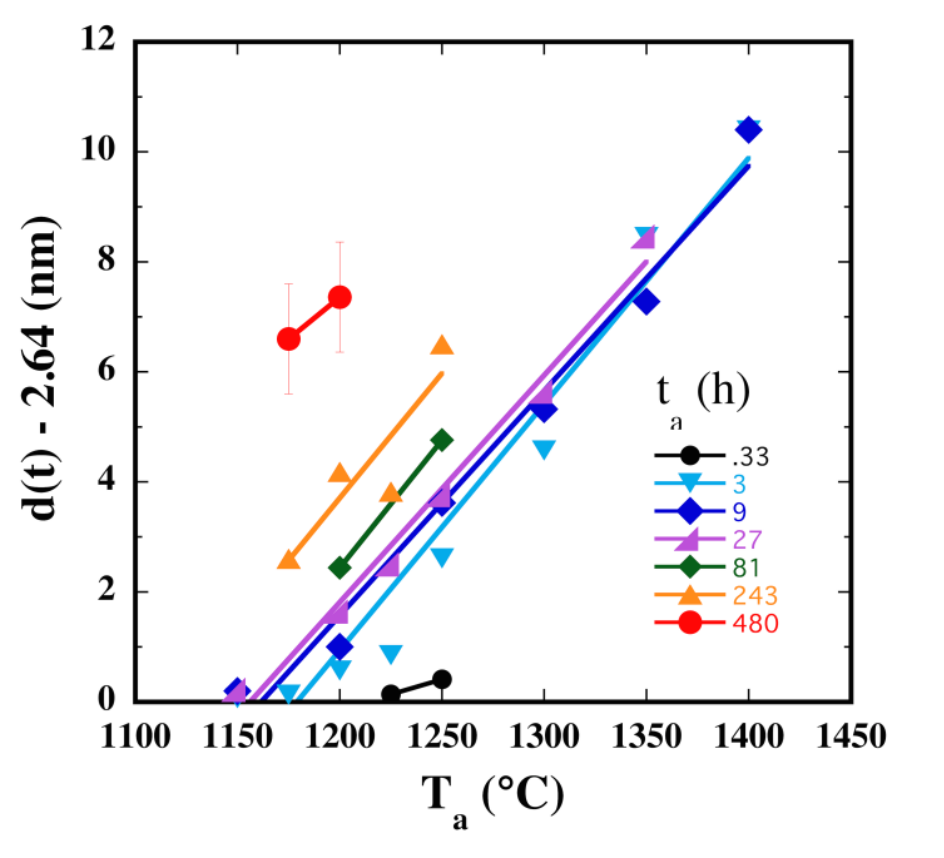

Figure 1. Coarsening trends in our SITA database $[9,10]$.

(12)

Figue

Figure (s)

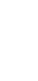

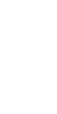

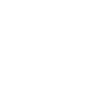

(1)

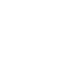



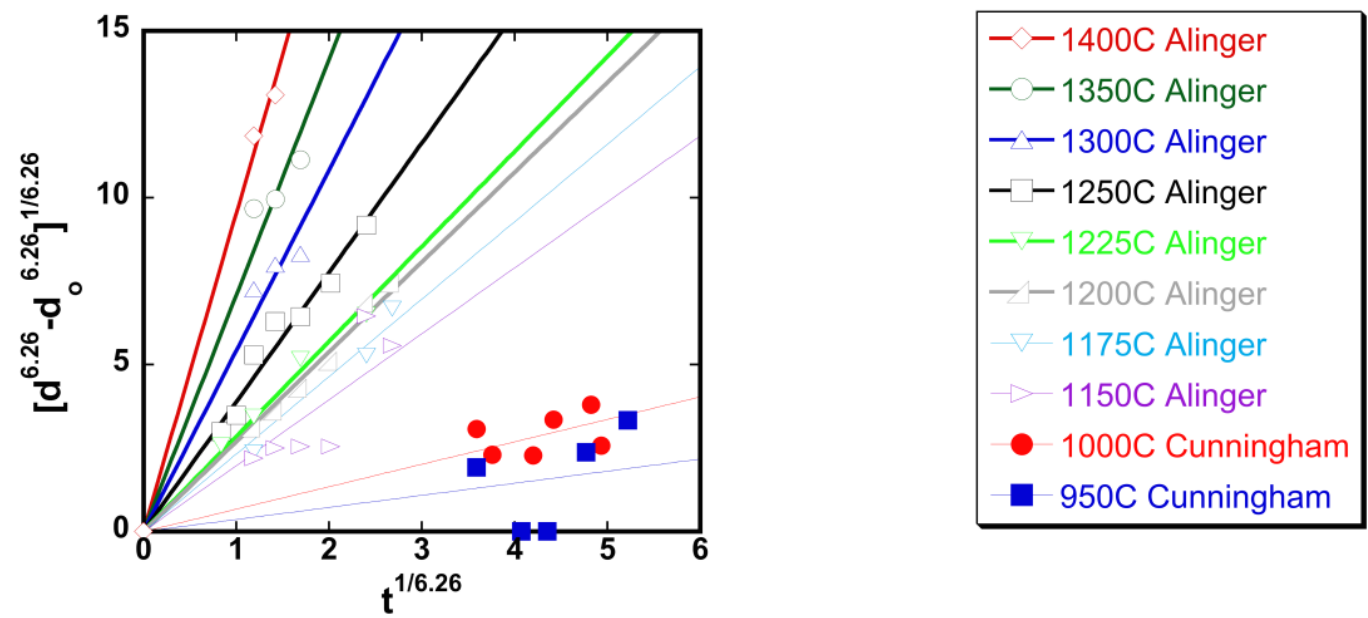

a)
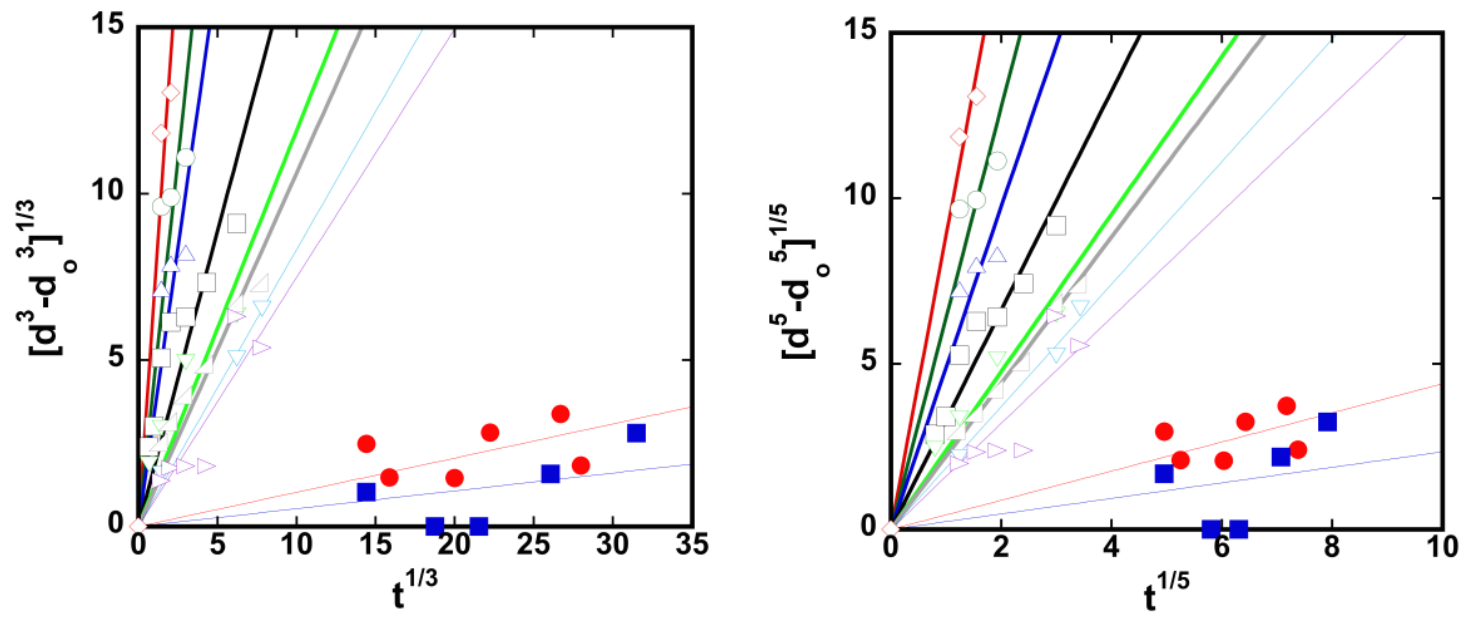

b)

c)

Figure 2. $\left[\mathrm{d}^{\mathrm{p}}-\mathrm{d}_{\mathrm{o}}^{\mathrm{p}}\right]^{1 / \mathrm{p}}=[\mathrm{Kt}]^{1 / \mathrm{p}}$ fits, where $\mathrm{K}$ is variously defined as: a) $\mathrm{k}_{\mathrm{o}} \exp (-$ $\left.\left.\mathrm{Q}_{0} / \mathrm{RT}\right).\right]^{1 / 6.26} ;\left[\mathrm{k}_{03} \exp \left(-\mathrm{Q}_{03} / \mathrm{RT}\right)\right]^{1 / 3} ;$ and, c) $\left[\mathrm{k}_{05} \exp \left(-\mathrm{Q}_{05} / \mathrm{RT}\right)\right]^{1 / 5}$. 


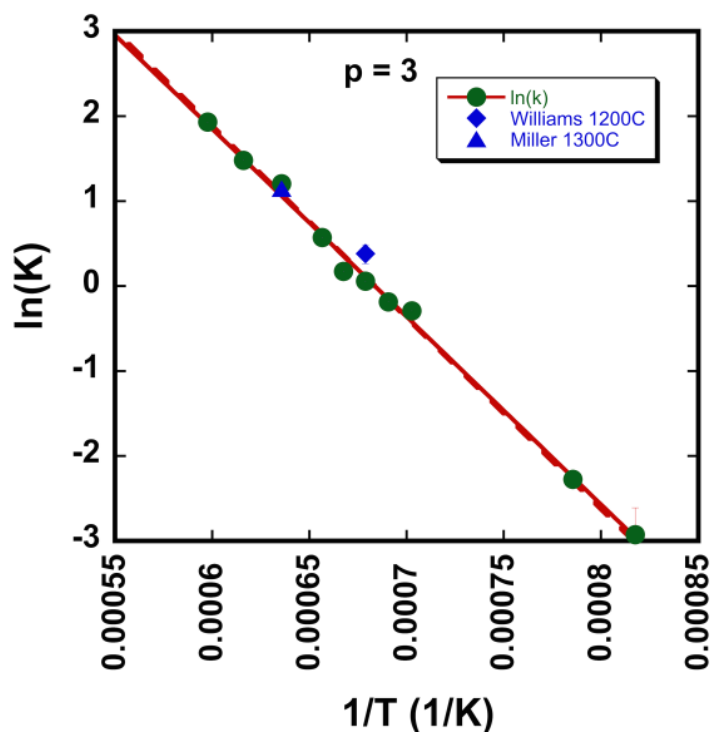

a)

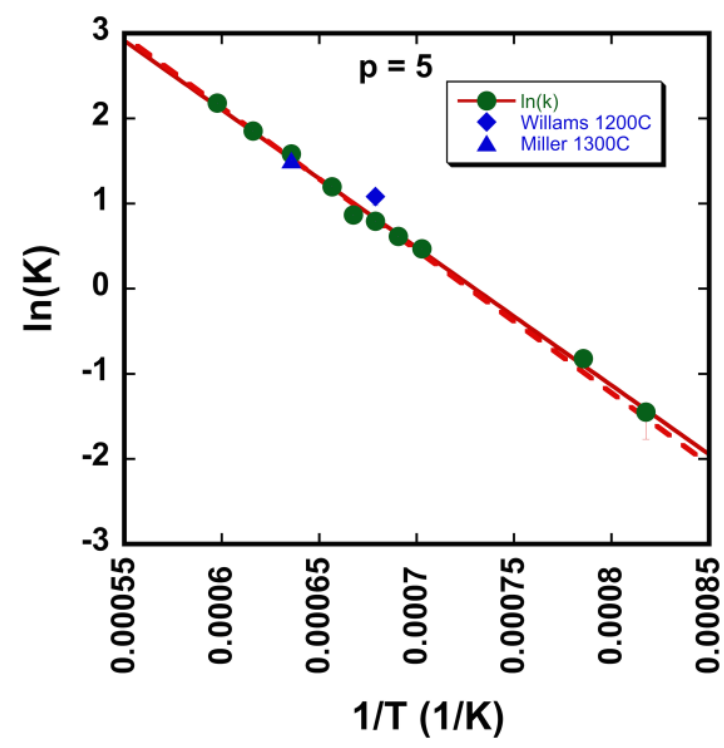

b)

Figure $3 . \ln (K)$ vs $1 /$ T plots for a) $p=3$ and $b$ ) $p=5$. 

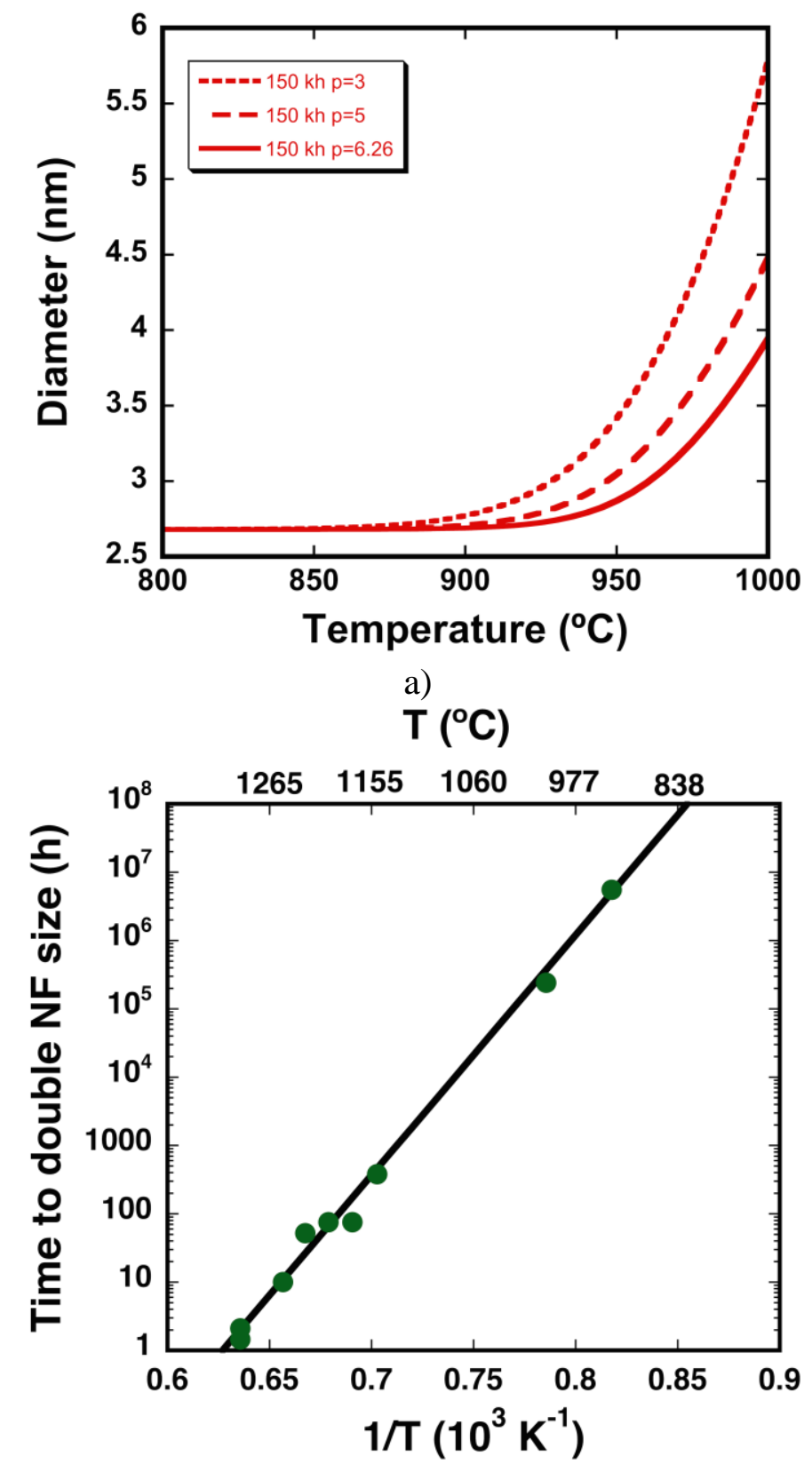

b)

Figure 4. a) Comparison between the predicted coarsening $\left(\mathrm{d}_{\mathrm{o}}=2.7 \mathrm{~nm}\right)$ vs. aging temperature for $150 \mathrm{kh}$ aging time for $\mathrm{p}=3,5$, and 6.26 ; $\mathrm{b}$ ) time to double NO size based on $\mathrm{p}=5$. 

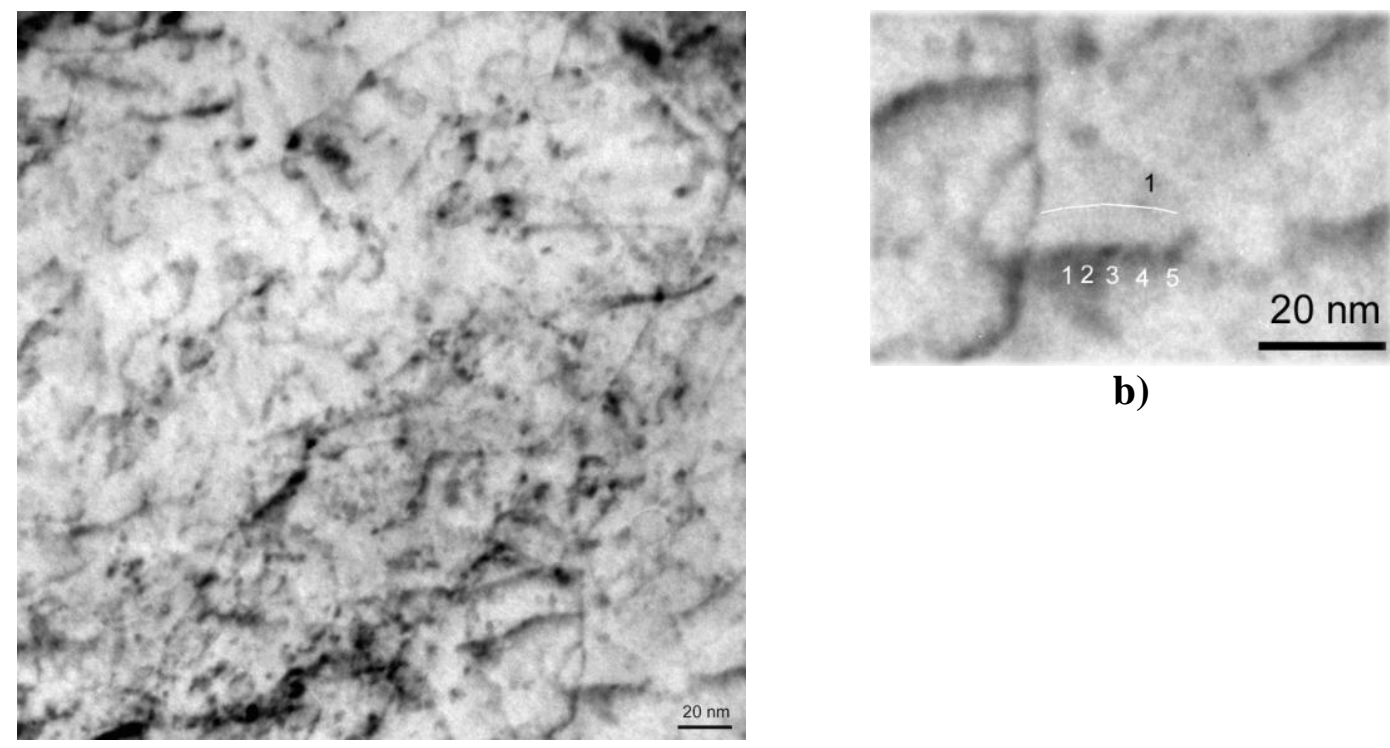

b)

a)

Figure 5. TEM micrographs showing high concentration of NO on dislocations a) at low magnification and $b$ ) at high magnification showing single NO (1 black) in matrix and multiple NO (1-5 white) lined up on a dislocation. 